\title{
Tazarotene 0.045\% Lotion for Acne: Formulation, Application Characteristics, and Clinical Efficacy and Safety
}

Zoe D Draelos, MD'; Emil A Tanghetti, MD²; Linda Stein Gold, MD³; Hilary Baldwin, MD4,5; Leon H Kircik, MD ${ }^{6,7,8}$; Eric Guenin, PharmD, PhD, MPH

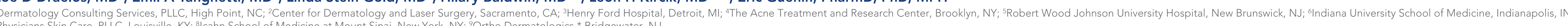

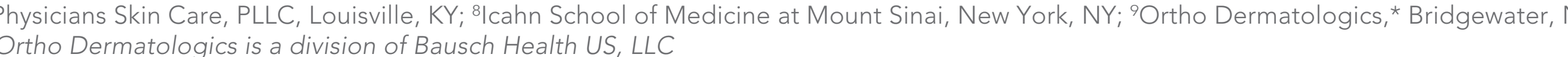

INTRODUCTION AND

FORMULATION

Tazarotene $0.045 \%$ lotion was developed

using polymeric emulsion technology to
provide uniform and rapid distribution of the

active ingredient and hydrating excipients

thazarotene into skin 1
tant

Tolerability may be improved by the vehicle

delivery as well as thegenous nature of the

tazarotene used compared with all other

arotene formulations

Polymeric Emulsion Technology for
Tazarotene $0.045 \%$ Lotion

$$
\begin{array}{ccc}
\text { (1) } \\
\text { 25.50um }
\end{array}
$$

PATIENT PREFERENCE

Healthy female participants aged

questionnaire on the properties of the
vehicle lotion for tazarotene $0.045 \%$

Results

Most participants (93-100\%) responded

favorably (strongly agree or agree) to all

questions about the various attrib
the vehicle lotion after application

My skin feels... Moisturized Smooth

Soft Rerushed

The product... Has a lightweight $\begin{gathered}\text { Absorbs } \\ \text { after feel } \\ \text { quickly }\end{gathered}$
SPREADABILITY:

TAZAROTENE $0.045 \%$ LOTION VS TRIFAROTENE $0.005 \%$ CREAM

- Skin coverage with tazarotene $0.045 \%$ lotion was compared to
trifarotene $0.005 \%$ cream in a double-blind split-body study of 30

trifarotene $0.005 \%$ cream in a dost
healthy adults (aged 18-59 years)

Each product $(0.1 \mathrm{~mL}$ ) was applied to a $10 \mathrm{~cm}$ wide area on one side of hen determined

Results

The average area of spread for tazarotene $0.045 \%$ lotion and

difference $\left.=36.7 \mathrm{~cm}^{2}: P<000\right)$

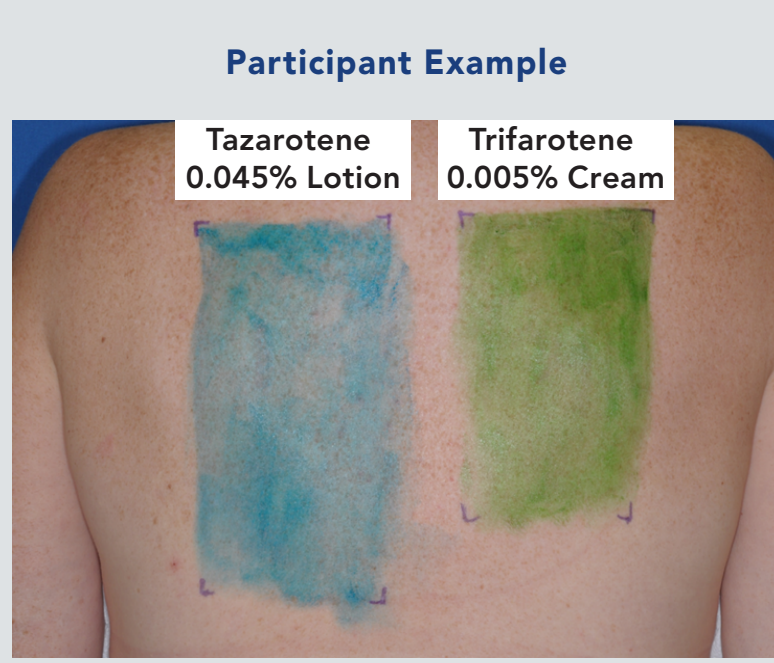

CORNEOMETRY AND

TRANSEPIDERMAL WATER LOSS (TEWL)

- Skin hydration and epidermal barrier maintenance with the vehicle lotion
were assessed through corneometry and TEWL $(\mathrm{N}=30)$ Results

- The vehicle lotion provided rapid and sustained increases in skin
moisturization (left) and improved barrier function (right)

Skin Moisturization Assessment
Using Corneometry (N=30)

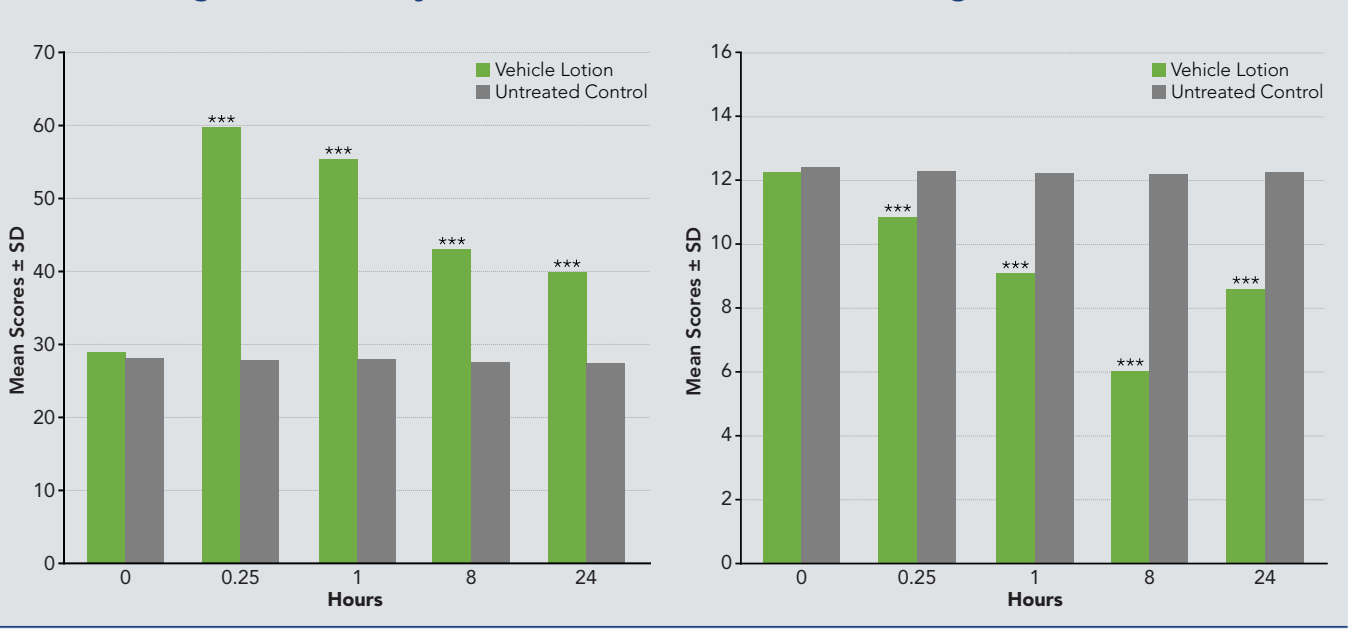

SKIN DEPOSITION:

TAZAROTENE $0.045 \%$ LOTION VS TAZAROTENE $0.1 \%$ CREAM

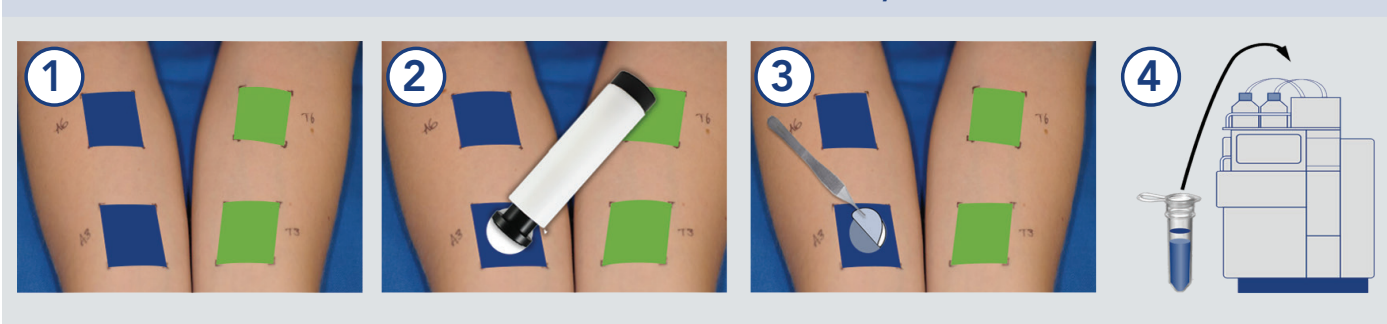

$1 \mathrm{~g}$ of each Post-application: Tape strips removed. Even-numbered

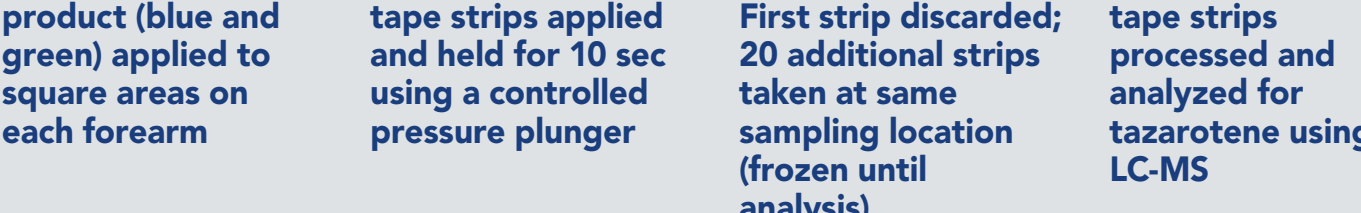

Results

10 female White participants aged 19-59 years completed the study

- At 6 hours post application, most tazarotene remained on the skin

surface, as indicated by the higher tazarotene concentrations recovered

- Concentration of tazarotene was approximately 2-fold higher for
$0.1 \%$ cream vs $0.045 \%$ lotion at both superficial and deep skin layers,
but the absolute difference drastically decreased in deeper layers

Tazarotene Tazarotene Cream minus Lotion

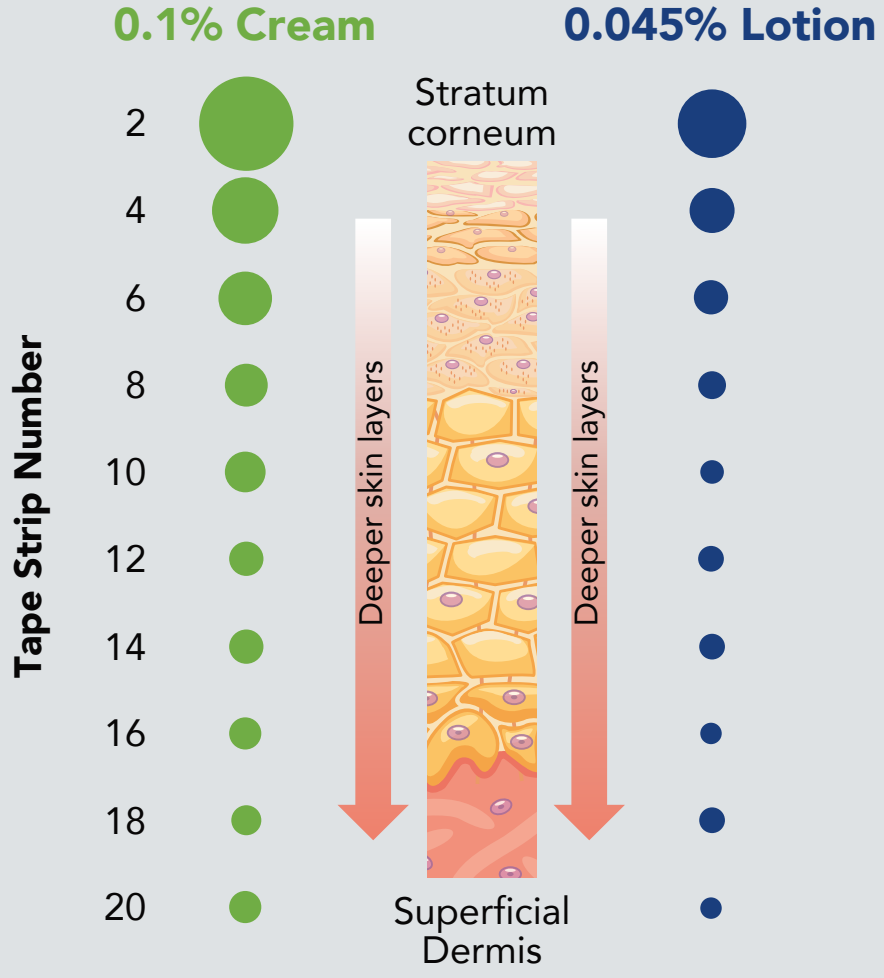

0.80

0.42

0.31

0.20

0.19

0.12

0.09

- Higher tazarotene concentrations remained at superficial vs deeper layers - Difference in concentration between formulations drastically decreased
in deeper layers

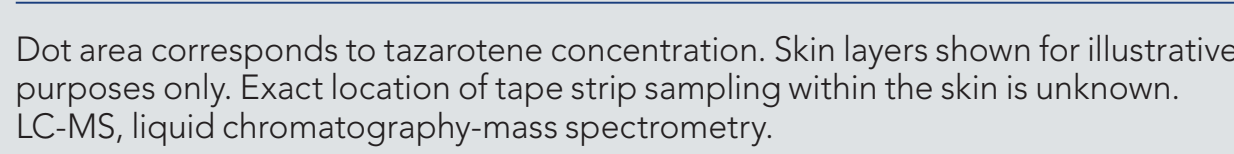

PHASE 2 STUDY:

- A total of 210 participants aged $\geq 2$ years with moderate-to-severe acn (2:2:1:1:1) to receive once-daily tazarotene $0.045 \%$ lotion, tazarotene $0.1 \%$ Results

- Tazarotene $0.045 \%$ lotion demonstrated significantly greater mean
percent reductions in inflammatory and nonifflammatory lesion counts percent reductions i
vs vehicle at week 12

Rates of treatment-emergent adverse events (TEAEs), serious adverse
events, and treatment-related TEAEs were lower with tazarotene $0.045 \%$ lotion compared with tazarotene $0.1 \%$ cream
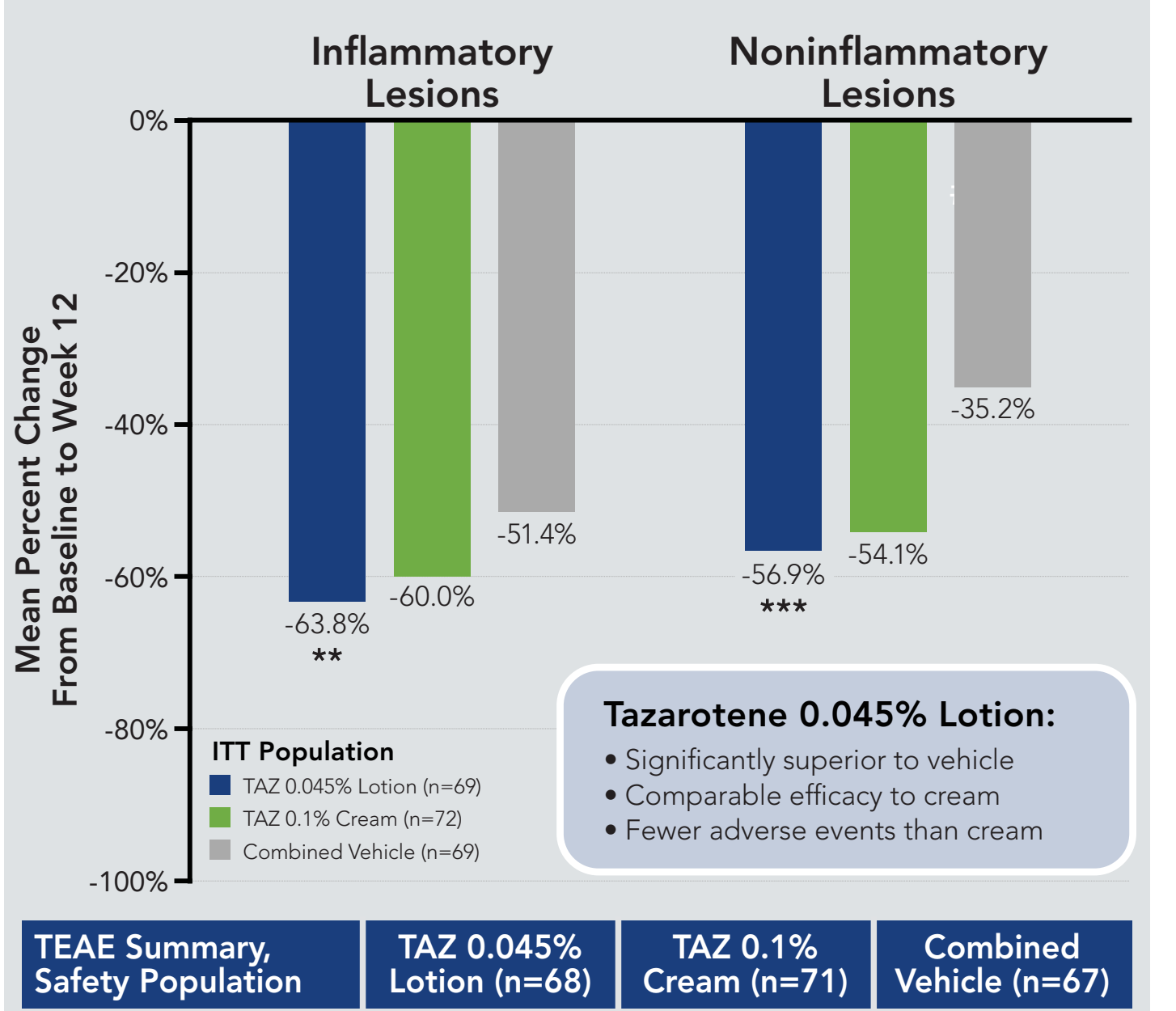

\begin{tabular}{|l|c|c|c|c|}
\hline Any TEAE & $14.7 \%$ & $26.8 \%$ & $13.4 \%$ \\
\hline
\end{tabular}

Any SAE

\begin{tabular}{|l|l|l|}
\hline $14.7 \%$ & $26.8 \%$ & $13.4 \%$ \\
\hline
\end{tabular}

\begin{tabular}{|l|c|c|c|}
$\begin{array}{l}\text { Any TEAE related to } \\
\text { treatment }\end{array}$ & $2.9 \%$ & $5.6 \%$ & $0 \%$ \\
\hline
\end{tabular}

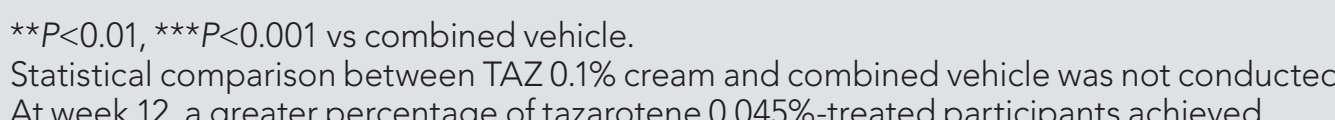

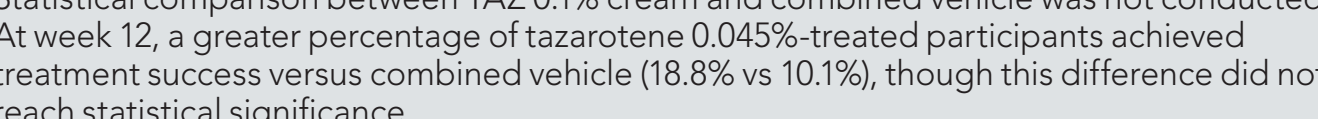

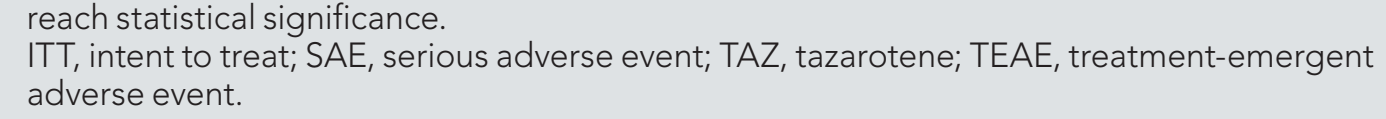

CONCLUSIONS

- Tazarotene $0.045 \%$ lotion utilizes

polymeric emulsion technology to

and skin barrier function

- This easy-to-apply lotion, with

sensory and aesthetic properties

ave grear skin coverage comp to

with trifarotene cream

- There is superior tolerability of

tazarotene $0.045 \%$ lotion versus

clinical efficacy

- Tazarotene is a potent activator of

retinoic acid gamma receptors

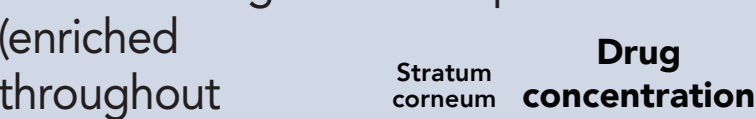

thin ${ }^{3}$ ); inus,
lowerlevels in

lower levels in

deeper skin with
tazarotene

0.045\% lotion

$0.1 \%$ cream are

sufficient for

- Superior

tazarotene

vs $0.1 \%$ cream

may be due

to lower drug

beneficial treatment option for acne

in patients aged 9 and older,

delivered in an easy-to-spread

formulation that can be applied to

ERERENCES

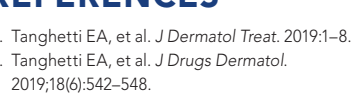

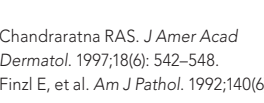

AUTHOR DISCLOSURES 